\title{
Functioning Characteristics of Patients with Neck Pain: ICF Concept Based
}

\author{
HaeJung Lee, JuMin Song \\ Department of Physical Therapy, College of Health and Welfare, Silla University, Busan, Korea
}

Purpose: This study examine the functioning level and quality of life (QoL) of people with non-specific neck pain and neck pain with radiculopathy using the neck disability index (NDI), functional rating index (FRI), and short form of health survey 36 (SF-36) and each of linked ICF code lists of those scales.

Methods: Each item of the NDI, FRI, and SF-36 were linked conceptually to the ICF code, and the ICF code lists of those scales were produced as iNDI, iFRI, and iSF-36, respectively. Seventy-nine patients with neck pain filled the instruments and its linked ICF code lists. The subjects were divided into two groups based on the diagnosis, non-specific neck pain (Group1), and neck pain with radiculopathy (Group2). A group comparison was performed using an independent t-test. The Pearson correlation coefficient was also used to analyze the relationships between each scale and the linked ICF code list.

Results: The participants in Group 2 experienced more difficulties in their daily activities than those in Group 2 when examined in NDI and FRI $(p<0.05)$. This result was also found consistently in the ICF code lists, iNDI and iFRI $(p=0.05)$. On the other hand, the QoL did not show a difference between groups $(p=0.06)$. A strong correlation was observed between the instruments and linked ICF code lists: NDI and iNDI $(r=0.90)$, FRI and iFRI $(r=0.91)$, and SF-36 and iSF-36 $(r=-0.61)$.

Conclusion: These findings suggest that the concept of each item in NDI and FRI could be linked to the ICF codes when examining patients with neck pain, but the items of SF-36 were found to be linked and expressed in ICF.

Keywords: ICF, Neck Pain, Functional Measurement

서 론

목통증은 약 $70 \%$ 성인이 겪는 가장 보편적인 근육뼈대계통의 질 병 중 하나로 퇴행성 변화, 신체적 요인(바르지 않은 자세, 반복적인 움직임 등) 및 심리사회적 요인(스트레스, 우울 등) 등에 의해 발생한 다고 보고된다. 목통증과 관련된 진단명에는 비특이적 목통증, 신경 뿌리병증, 채찍질 손상, 긴장성 두통 등이 있다.2

목의 신경뿌리병증은 어깨와 팔까지 통증이 뻗어내리는 신경학적 증상을 동반하는 목통증으로 정의되고, 비특이적 목통증은 골절, 염 증, 감염 등과 같은 특정 병리를 제외하고 신경학적 증상을 동반하지 않는 목 부위의 통증을 의미한다. 목통증으로 내원한 환자 중 특정 을 병인을 제외한 약 $15 \%$ 가 신경뿌리병증으로 진단되고, 약 $80 \%$ 의 환 자는 비특이적 목통증으로 진단을 받는다. 목통증은 일상생활에서 의 기능수행을 제한하고 직업수행 능력을 감소시키며, 증가된 건강 관리비용 부담은 사회적 문제를 야기한다.,5
목통증으로 인한 기능수행정도를 측정하는 평가도구에는 Nortwick-Park neck pain questionnaire, Copenhagen neck functional disability, Neck pain and disability scale 등을 포함하여 다양하게 보고되고 있 다. 목장애지수(neck disability index, NDI)는 일상생활에서의 목통증 으로 인한 기능제한을 평가하는 도구로 가장 보편적으로 사용되고 있다. ${ }^{6}$ 기능적평가지수(functional rating index, FRI)는 척주근육뼈대계 통의 통증과 기능을 평가하는 도구로서 허리통증과 목통증이 있는 환자 모두에게 적용할 수 있다. 최근 환자의 삶의 질 평가의 중요성에 대한 관심이 높아지고 있으며, 많은 연구에서 특정질병평가도구와 삶 의 질 사이의 연관성을 평가하고 있다. ${ }^{8} \mathrm{SF}-36$ 은 건강관련 삶의 질을 평가하는데 가장 보편적으로 활용되는 환자 보고형 설문지이다. ${ }^{9}$

기능수행평가는 질병의 진단과 함께 환자의 건강상태와 장애정도 를 파악하기 위해 임상에서 일반적으로 수행되고 기능수행관련정보 는 임상진료, 서비스 개정, 관리 및 정책 등 의료시스템의 모든 수준에 서 필수적이다. 세계보건기구(WHO)는 질병과 손상으로 인한 기능수
Received Jul 8, 2019 Revised Aug 23, 2019

Accepted Aug 29, 2019

Corresponding author JuMin Song

E-mail jmsong@silla.ac.kr
Copylight (C)2019 The Korean Society of Physical Therapy

This is an Open Access article distribute under the terms of the Creative Commons Attribution Non-commercial License (Http:// creativecommons.org/license/by-nc/4.o.) which permits unrestricted non-commercial use, distribution, and reproduction in any medium, provided the original work is properly cited. 
행정도를 표현할 수 있는 장애모델과 정보시스템의 필요성을 인식하 여 신체기능과 구조, 활동과 참여 및 환경 요인의 4 개 영역으로 체계 화된 표준분류인 국제기능장애건강분류(international classification of functioning, disability and health, ICF)를 개발하였다. ${ }^{10}$ 재활영역에서 생물심리사회적 모델을 기반으로 하는 ICF를 개념의 틀로 사용하여 질병의 결과를 분류하고 재활목표를 구조화하는 것이 보편화되고 있 다.11 또한 임상영역에서 사용하는 기능수행 측정도구는 개인의 일상 생활에서 환경을 포함한 다양한 측면을 고려하여 평가할 수 있는 ICF 모델이 반영되어야 한다는 주장이 제기되고 있다.12 이를 위해서 측정 도구의 문항과 ICF 코드와의 개념 연결은 측정도구의 구성특성을 분 석하고, 연결된 ICF 코드와 각 측정도구가 서로 연관성이 있는지 즉, 측정하고자 하는 내용이 유사한지를 확인하기 위해 필요하다. ${ }^{13}$

본 연구는 진단명에 따른 기능수행정도와 삶의 질의 정도가 차이가 있는지 확인하기 위해 신경뿌리병증으로 인한 목통증환자와 비특이적 목통증으로 진단받은 환자의 기능수행과 삶의 질을 분석하고, 또한 표 준화된 분류체계인 ICF에서도 일반측정도구와 같은 결과를 보여주는 지 확인하기 위해 각 도구의 문항과 개념적으로 연결되는 ICF 코드 리 스트와분류척도(qualifier)를 사용하여 분석하기 위해 수행되었다.

\section{방 법}

\section{1. 대상자}

목통증을 호소하고 병원에서 물리치료 서비스를 받고 있는 18 세 이 상 성인 환자를 대상으로 하였다. 어깨와 팔까지 통증이 뻗어내리는 신경학적 증상을 동반하는 목통증을 동반하여 신경뿌리병증으로 진단 받은 환자와 골절, 염증, 감염 등과 같은 특정 병리를 제외하고 신경학적 증상을 동반하지 않는 목통증을 호소하는 비특이적 목통 증 환자를 포함하였다. 골절, 암, 뇌졸중을 포함한 중추신경계 손상 을 포함한 특정질환이 있는 환자는 제외하였다. 신라대학교 연구윤 리위원회의 승인을 받았으며, 모든 연구대상자에게 본 연구에 대해 설명을 하고 데이터 수집 전에 참여동의서를 받았다.

\section{2. 실험방법}

본 연구는 신경뿌리병증이나 비특이적 목통증으로 진단받은 목 통증 환자의 기능수행정도와 삶의 질에 대한 정보를 수집하여 분석 한 단면연구설계이다. 데이터수집은 약 1 개월동안 실시하였다.

\section{1) 측정도구}

(1) 목장애지수(neck disability index, NDI) ${ }^{14}$

목통증으로 인해 일상생활에서 겪는 어려움을 평가하기 위한 도구 로 10 개의 문항으로 구성되어 있다. 통증의 정도, 자기관리, 물건 들어
올리기, 책 읽기, 두통, 집중력, 일하기, 운전, 잠자기, 여가활동에 대한 문항을 포함하고 있다. 문항당 점수는 0-5점으로 총점은 50점이며, 총 점이 높을수록 장애가 심한 것을 의미한다. 목통증 환자 평가에 높 은 신뢰도와타당도가 보고되고 있다.

(2) 기능적평가지수(functional rating index, FRI) ${ }^{14}$

오스웨스트리허리장애지수와 목장애지수를 구성하고 있는 문항 중 두 평가도구에 공통으로 포함된 문항을 선택하여 만들어진 기능수 행평가도구로서 허리통증과 목통증 환자에게 사용된다. 통증, 수면, 자기관리, 이동, 일, 여가활동, 물건 들어올리기, 걷기 및 서있기를 포 함한 10 개 문항으로 구성되어 있다. 문항 당 0 에서 4 점 척도를 사용하 여 총점은 40 점이고 점수가 높을수록 심한 장애정도를 나타낸다. 목 통증과 허리통증 환자 두 그룹 모두에서 높은 신뢰도와 타당도가 보 고되었다.

(3) 삶의 질 평가(short form-36 health survey, SF-36) ${ }^{9}$ 건강관련 삶의 질을 평가하는 도구로 8 개 영역의 36 개 문항으로 구성 되어 있으며, 생활 활력, 신체기능수행, 통증, 일반적인 건강인식, 신체 역할수행, 정서역할수행, 사회역할수행, 정신건강상태에 대해 평가한 다. 점수가 높을수록 삶의 질이 높은 것을 의미하고, 보건의료 영역에 서 가장 많이 사용되는 도구로 신뢰도와 타당도가 높은 것으로 보고 되었다.

(4) 측정도구의 항목과 연결된 ICF 코드 리스트(iNDI, iFRI, iSF-36) $\mathrm{ICF}$ 코드 리스트는 위의 측정도구들이 포함하는 각각의 문항과 개념 적으로 연결되는 ICF 코드를 선택하여 각 측정도구의 ICF 코드 리스 트를 구성하였다. 도구를 구성하는 문항의 개념이란 도구가 측정하 고자 하는 내용을 의미한다. ICF 연결과정은 선행연구에서 자세히 보고하였다.13 구성된 각각의 ICF 코드 리스트를 iNDI, iFRI, iSF-36라 고 본 연구에서는 명명하였다. 연결된 코드는 0 에서 4 점 분류척도 (qualifier)를 사용하였으며 각 리스트의 총점은 iNDI 48점, iFRI 52점,

Table 1. Means and standard deviations of NDI, FRI, SF-36, and each of linked ICF code lists. $(n=79)$

\begin{tabular}{lccc}
\hline Scales & Group 1 $(n=58)$ & Group 2 $(n=21)$ & P-value \\
\hline NDI & $22.07 \pm 8.26$ & $27.52 \pm 11.50$ & 0.02 \\
FRI & $10.75 \pm 7.30$ & $15.42 \pm 9.39$ & 0.02 \\
SF-36 & $49.57 \pm 11.46$ & $44.25 \pm 9.63$ & 0.06 \\
iNDI & $11.75 \pm 9.08$ & $18.47 \pm 12.52$ & 0.03 \\
iFRI & $10.96 \pm 9.75$ & $18.52 \pm 14.08$ & 0.03 \\
iSF-36 & $15.41 \pm 13.58$ & $25.66 \pm 18.15$ & 0.01 \\
\hline
\end{tabular}

NDI: neck disability index, FRI: functional rating index, SF-36: short form-36 health survey, iNDI: ICF code list linked to NDI, iFRI: ICF code list linked to FRI, iSF36: ICF code list linked to SF-36. 
iSF-36 68점으로, 점수가 높을수록 어려움이 많거나 장애정도가 심 한 것을 뜻한다.

\section{(5) 임상 데이터 수집}

목통증으로 진단을 받고 물리치료 서비스를 이용하고 있는 환자를 대 상으로 NDI, FRI, SF-36 및 각 도구의 항목과 연결된 ICF 코드 리스트를 사용하여 임상데이터를 수집하였다. 데이터 수집은 부산, 창원, 대구, 대전, 울산, 광주, 제주시 소재의 종합병원과 개인병원을 포함한 12 개 의 의료기관에서 목통증으로 진단받은 환자를 대상으로 실시되었다. 3 년 이상의 임상경력을 가진 물리치료사가 데이터수집을 실시하였다. 데이터수집에서 발생할 수 있는 비뚤림을 최소화하기 위해 데이터 수 집 이후 진단명에 따라 비특이적 목통증그룹(그룹 1)과 신경뿌리병목 통증그룹(그룹 2)으로 분류하였다. 진단명에 따라 기능수행정도와 삶 의 질이 다른지를 확인하기 위해 두 그룹으로 나눠 분석하였다.

\section{3. 자료분석}

대상자의 일반적인 특성과 측정결과는 기술통계로 분석하였다. 연결 $\mathrm{ICF}$ 코드 리스트와 각 측정도구 사이의 연관성을 확인하기 위해 피 어슨상관계수를 산출하였으며 그룹간의 비교를 위해 독립표본 $\mathrm{t}$ 검 증을 실시하였다. 유의수준은 0.05 로 설정하였으며, 본 연구의 분석 은 IBM SPSS 24 버전(SPSS Inc, Chicago)을 사용하였다.

\section{결 과}

\section{1. 대상자의 특성}

본 연구기간 동안 목통증으로 치료를 받고 있는 환자 중 데이터수집 에 참여한 대상자는 총 82 명이었다. 이중 골절(2명)과 환축관절아탈 구(1명)을 제외하였다. 따라서 79명(여: 45)의 목통증환자의 데이터를 분석하였다. 대상자 중 58명은 비특이적 목통증(그룹 1)으로 진단받

Table 2. Mapping of items in NDI, FRI and SF-36 into ICF codes. Concepts within each item in NDI, FRI and SF-36 were compared to the concepts in ICF codes in order to link them together

\begin{tabular}{|c|c|c|c|c|}
\hline NDI (Item Number) & FRI (Item Number) & SF-36 (Item Number) & Concept & ICF category \\
\hline & & $\begin{array}{l}\text { - Pep, energy, fatigue, tired } \\
\quad(23,27,29,31)\end{array}$ & - energy, fatigue & - b130 Energy and driving function \\
\hline • Sleeping (9) & • Sleeping (2) & & • sleep & • b134 Sleep functions \\
\hline \multirow[t]{2}{*}{ • Concentration (6) } & & • careful (19) & - attention & • b140 Attention function \\
\hline & & $\begin{array}{l}\text { - anxious, nervous, sad, calm, } \\
\text { peaceful, happy, } \\
\text { downhearted } \\
(17-19,20,24-26,28,30,32)\end{array}$ & • emotion & • b152 Emotional function \\
\hline - Pain intensity (1) & $\begin{array}{l}\text { - Pain intensity (1), } \\
\text { pain frequency (7) }\end{array}$ & $\cdot$ pain $(21,22)$ & - pain & - b280 Sensation of pain \\
\hline \multirow[t]{5}{*}{ - Headache (5) } & & & - pain in the neck & • b28010 Pain in head and neck \\
\hline & & - daily activities (13-16, 17-19) & • daily activities & - d230 Carrying out daily routine \\
\hline & & - bending, kneeling, stooping (8) & - changing positions & $\begin{array}{l}\text { - d410 Changing basic body } \\
\text { position }\end{array}$ \\
\hline & - Standing (10) & & - standing & $\cdot d 4104$ Standing \\
\hline & & & & $\begin{array}{l}\cdot \mathrm{d} 4154 \text { Maintaining a } \\
\text { standing position }\end{array}$ \\
\hline • Reading (4) & & & & - d4155 Maintaining head position \\
\hline \multirow[t]{5}{*}{ - Lifting, carrying (3) } & & • lifting, carrying (3-5) & - lifting or carrying an object & - d430 Lifting and carrying objects \\
\hline & • Lifting (8) & & & • d4300 Lifting \\
\hline & • Walking (9) & • walking (9-11) & • walking & • d450 Walking \\
\hline & & • climbing (6-7), running (3) & • climbing, running & $\cdot d 455$ Moving around \\
\hline & - Travelling (4) & & - using transportation & - d470 Using transportation \\
\hline • Driving (8) & • Driving (4) & & • drive & • d475 Driving \\
\hline \multirow[t]{3}{*}{$\begin{array}{l}\text { - Personal care, washing, } \\
\text { dressing (2) }\end{array}$} & $\begin{array}{l}\text { - Personal care, washing, } \\
\text { dressing ( } 3 \text { ) }\end{array}$ & & - self-care, washing, dressing & - d5 Self-care, \\
\hline & & • bathing (12) & & - d510 Washing, \\
\hline & & • dressing (12) & & • d540 Dressing \\
\hline \multirow[t]{4}{*}{ - Work (7) } & • Work (5) & • house work (22) & $\begin{array}{l}\text { - usual work including housework, } \\
\text { job task }\end{array}$ & • d640 Doing housework, \\
\hline & & & & d8451 Maintaining a job \\
\hline & & $\begin{array}{l}\text { - social activity with others } \\
(20,32)\end{array}$ & $\begin{array}{l}\text { - doing social activities with } \\
\text { family and friends }\end{array}$ & $\begin{array}{l}\text { - d750 Informal social relationships, } \\
\text { d760 Family relationships }\end{array}$ \\
\hline & & • work $(13-16,17-19)$ & • work & - d850 Remunerative employment \\
\hline - Recreation (10) & - Recreation (6) & - strenuous sport, bowling (3-4) & - recreational activities & • d920 Recreation and leisure \\
\hline
\end{tabular}


았고, 나머지 19명은 신경뿌리병증으로 인한 목통증(그룹 2)으로 진 단을 받았다. 각 군의 평균나이는 36.5 세 $( \pm 14.3), 43.2$ 세 $( \pm 12.4)$ 이었다.

\section{2. 그룹 간 비교}

측정도구를 사용한 평가결과는 표 1 에 제시하였다. NDI와 FRI로 측 정된 기능수행 정도에서는 그룹간 차이가 관찰되었으나 $(\mathrm{p}<0.05)$ SF-36으로 측정한 삶의 질에 대한 결과는 그룹 간 차이가 없었다 $(\mathrm{p}=0.06)$. iNDI, iFRI 및 iSF-36로 측정한 기능수행정도 및 삶의 질에 대한 결과에서도 두 그룹간 차이가 관찰되었다 $(\mathrm{p}<0.05)$.

\section{NDI, FRI 및 SF-36의 문항과 ICF 코드 연결}

$\mathrm{NDI}$ 의 10 개 문항은 12 개의 ICF 코드와 1 개의 장과 개념적으로 연결 되었고, 10 개의 문항으로 구성된 FRI는 13 개의 ICF 코드, 1 개의 장과 직접 연결되었다. SF-36의 문항 중 29 개의 문항만이 17 개의 ICF 코드 와 개념적으로 연결되었다(Table 2).

\section{NDI, FRI 및 SF-36과 각 도구 ICF 코드 리스트의 상관관계}

각 도구와 연결된 ICF 코드 리스트와의 상관관계분석 결과는 그림 1 에 보고하였다. NDI와 FRI는 각각의 연결된 ICF 코드 리스트와 매우 높은 양의 상관관계가 관찰되었다(각각 $r=.90, r=.91$ ). SF-36은 연결 $\mathrm{ICF}$ 코드 리스트 결과 값과 중간 정도의 음의 상관관계가 나타났다 $(r=-.61)$.

\section{고 찰}

본 연구는 진단명에 따른 기능수행정도와 삶의 질의 정도에서 차이 가 나는지 확인하기 위해 신경뿌리병증으로 인한 목통증환자와 비 특이적 목통증으로 진단받은 환자의 기능수행과 삶의 질의 정도를 평가하여 비교 분석하였다. 기능수행에 대한 정보는 임상과 관련 연 구에서 보편적으로 가장 많이 사용되는 NDI와 FRI, 삶의 질은 SF-36 을 사용하여 수집하였다. 또한 표준화된 분류체계인 ICF에서도 일반 측정도구와 같은 결과를 보여주는지 확인하기 위해 각 도구와 개념
적으로 연결된 ICF 코드 리스트도 활용하였다.

본 연구에서는 목통증으로 물리치료 서비스를 이용하는 환자를 대상으로 NDI, FRI, SF-36 및 연결된 ICF 코드 리스트를 사용하여 정 보를 수집한 다음 비특이적 목통증그룹과 신경뿌리병증 목통증그룹 으로 나누어 결과를 비교 분석하였다. 환자의 진단명에 따라 통증, 기 능수행 또는 정서적 영향이 다를 것이라는 평가자의 비뚤림을 최소 화하기 위해 통증, 기능수행, 삶의 질에 대한 정보를 수집한 다음 대 상자의 진단명에 따라 그룹을 나누어 수집한 정보를 비교하였다.

본 연구기간 동안 목통증으로 물리치료 서비스를 이용하는 환자 를 대상으로 데이터수집한 결과 대상자의 약 $25 \%$ 의 대상자가 신경뿌 리병증으로 진단을 받았으며, 나머지 대상자 약 $75 \%$ 는 비특이적 목 통증으로 진단을 받았다. 이러한 결과는 선행연구의 보고와 유사하 였다. ${ }^{3}$

본 연구에서 신경뿌리병증 목통증그룹과 비특이적 목통증그룹의 기능수행정도에서 차이가 관찰되었다. 증상에 따라 진단이 달라질 수 있고 특정 증상의 정도는 기능수행에 영향을 줄 수 있다. 예를 들 어 단순히 목통증만 있는 환자와 목 부위의 통증과 함께 팔로 뻗는 통증이 동반되고 감각과 근력의 변화가 있는 환자는 일상생할에서 겪는 어려움의 범위나 정도가 다를 것으로 생각된다. 이는 본 연구에 서 진단이 다른 두 그룹에서의 NDI, FRI, iNDI 및 iFRI의 그룹간 비교 결과에서 확인할 수 있었다. 그러나 SF-36으로 측정한 삶의 질에 대한 결과는 그룹간 차이가 관찰되지 않았으며 이는 각 그룹의 대상자들 의 건강상태는 그룹간의 삶의 질에 차이를 나타낼 만큼 차이가 나타 나지 않았기 때문으로 판단된다. SF-36의 결과와는 다르게 iSF-36은 두 그룹간에 차이가 관찰되었다. ${ }^{13}$ 이는 SF-36과 ICF 연결 결과에서 보 여지는 바와 같이 SF-36을 구성하고 있는 문항의 개념들이 ICF 코드 로 연결되는 과정에서 그 특성의 반영이 제한되어 나타난 결과라고 생각된다.

목통증 환자의 기능수행정도를 평가하는 NDI는 ICF와 개념적으 로 잘 연결되는 것으로 확인되었다. 전체 10 개 문항 중 4 개의 문항(수 면, 주의력, 통증 강도, 두통)은 4개의 신체기능영역 ICF 코드와 일대 일로 연결되었다. 나머지 6 개의 문항은 자기관리에 대한 1 개의 장 및
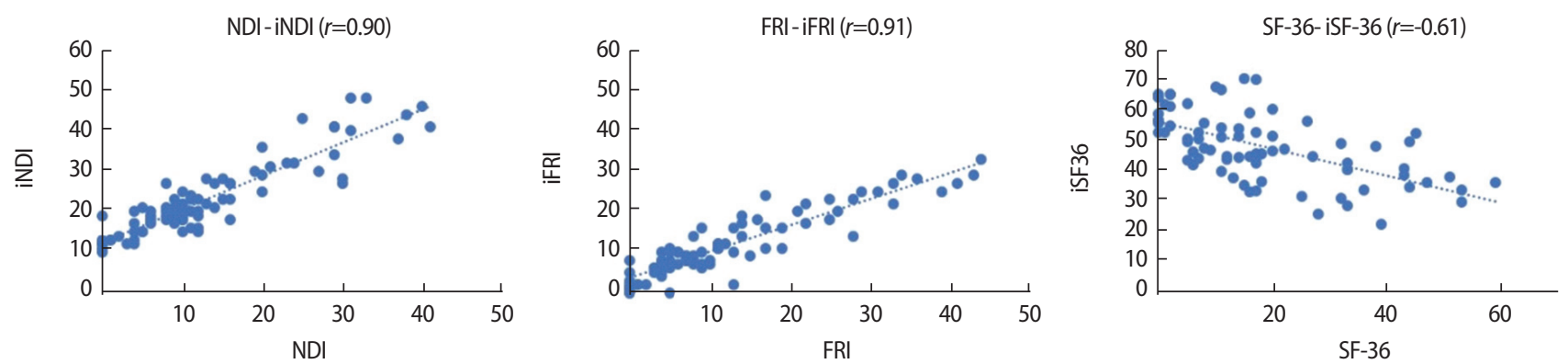

Figure 1. Correlation between each tool and its linked ICF code list 
8 개의 활동과 참여 영역의 ICF 코드와 개념적으로 연결되었다. 들기 와나르기, 운전하기 및 여가활동은 3 개의 활동과 참여 영역의 ICF 코 드와 일대일로 연결이 되었다. NDI의 읽기에 대한 문항은 ICF 코드 “d4155 머리자세 유지하기”와 연결하였다. 이 항목의 개념은 ICF 코드 "d166 읽기”의 개념과는 다르게 읽기 활동을 위해 일정 시간 동안 머 리의 자세를 유지할 수 있는지 묻기 위한 문항으로 판단하였다. 일에 대한 문항은 일의 개념을 집안 일과 직장 업무로 추출하여 ICF 코드 “d640 집안일 하기”와 “d8451 근속하기”에 연결하였다. NDI의 자기관 리에 대한 문항에는 씻기와 옷 입기 예시가 포함되어 있어 예시에 대 한 개념도 독립적으로 연결하여 15 하나의 문항이 1 개의 장 “5장 자기 관리”와 2개의 ICF 코드 ”d510 씻기”와 “d540 옷 입기”와 연결하였다. 선행연구에서도 같은 결과가 보고되었다. ${ }^{16}$ 문항과 ICF코드 연결 결 과는 NDI와 $\mathrm{iNDI}$ 의 상관관계 결과에서도 확인할 수 있다.

척주근육뼈대계통의 통증과 기능수행을 평가하는 FRI의 문항에 서 측정하고자 하는 내용 즉 개념이 ICF 코드와 전반적으로 연결이 되는 것을 확인할 수 있었고 이는 FRI와 iFRI의 상관관계 결과에서도 관찰되었다. 수면, 들어올리기, 걷기 및 여가활동에 대한 문항은 해당 개념의 ICF 코드에 일대일로 연결이 되었다. FRI의 통증에 대한 2개의 문항은 모두 ICF 코드 “b280 통증”에 연결하였다. b280의 통증은 통증 이 있는 신체의 부위로 정의되므로 FRI에서 평가하고자 하는 통증의 강도와 빈도는 직접적으로 ICF 코드와 연결하는 데는 제한적이며, 이 는 해당 코드에서 분류척도로 표현하는 것이 더 적절하다고 생각된 다. ${ }^{17}$ 서기와 관련된 문항은 2 개의 ICF 코드 "d4104 서기”와 "d4154 선 자세 유지하기"와 연결되었다. FRI는 척주의 기능을 평가하는 도구이 므로 이는 문항의 개념이 서고 선 자세를 유지하는 것 모두를 포함하 는 것으로 판단되기 때문이다. ${ }^{18}$ 이동과 관련된 문항에서 주어진 예시 인 운전하기도 개념으로 추출하여 하나의 문항이 2 개의 ICF 코드 “d470 교통수단 이용하기”와 “d475 운전하기”로 연결하였다. ${ }^{16}$ 일에 대 한 문항과 자기관리에 대한 문항은 위의 NDI 결과와 동일하였다.

SF-36의 문항 중 일상생활에서의 기능수행에 대한 개념을 포함하 는 29 개의 문항은 17 개의 ICF 코드와 연결되었다. 이는 SF-36에서 평 가하고자 하는 내용을 연결된 ICF 코드만으로는 충분히 표현할 수 없다는 것을 의미한다. ${ }^{13}$ 또한 대상자의 일반적인 건강상태나 건강상 태에 대한 인지, 신체적 어려움 및 정서적 어려움 등의 항목들도 직접 적으로 연결되는 ICF 코드를 찾지못하였다. SF-36은 ICF 코드로 표현 하기에는 제한적인 것으로 사료된다. ${ }^{18}$ 그러나 SF-36과 iSF-36사이에 서 높은 상관관계가 관찰되었다. 이러한 결과는 실제 두 변수 사이에 서의 관련성보다는 두 변수의 변화 동향을 나타내는 상관관계의 특 성이 반영된 결과로 사료된다.

본 연구에서는 질병 특이적 측정도구의 결과와 측정도구의 문항 과 연결한 ICF 코드 리스트를 구성한 코드에 분류척도를 사용하여
진단명이 다른 두 그룹의 대상자의 데이터를 수집하여 비교 분석한 결과 일상생활에서 경험하는 기능수행정도에는 차이를 관찰할 수 있었다. 이는 NDI와 FRI가 가지는 개념을 ICF의 개념으로 연결됨을 보여줄 뿐만 아니라, 본 연구에서 확인한 분류척도를 사용한 ICF 코 드 리스트의 결과는 NDI와 FRI로 표현된 기능수행정도와 연결됨을 보여준다. 이는 ICF의 임상적용가능성을 확인할 수 있었으며, 의료정 보표준화의 기여할 수 있을 것으로 사료된다.

\section{REFERENCES}

1. Strine TW, HootmanJ M. Us national prevalence and correlates of low back and neck pain among adults. Arthritis Rheu. 2007;57(4):656-65.

2. Borghouts JA, Koes BW, Bouter LM. The clinical course and prognostic factors of non-specific neck pain: A systematic review. Pain. 1998; 77(1):1-13.

3. Waddell G. The back pain revolution. 2nd. London, Churchill Livingstone, 2004.

4. Hoy D, March L, Woolf A et al. The global burden of neck pain: Estimates from the global burden of disease 2010 study. Ann Rheum Dis. 2014;73(7):1309-15.

5. Council. NR. Musculoskeletal disorders and the workplace. Washington D.C. National Academies Press. 2001.

6. Bobos P, MacDermid JC, Walton DM et al. Patient-reported outcome measures used for neck disorders: An overview of systematic reviews. J Orthop Sports Phys Ther. 2018;48(10):775-88.

7. Bai Z, Shu T, Lu J et al. Measurement properties of the functional rating index: A systematic review and meta-analysis. Spine. 2018;43(22): E1340-E9.

8. Le J, Dorstyn DS, Mpfou E et al. Health-related quality of life in coronary heart disease: A systematic review and meta-analysis mapped against the international classification of functioning, disability and health. Qual Life Res. 2018;27(10):2491-503.

9. Ware JE. Sf-36 health survey update. Spine. 2000;25(24):3130-9.

10. Organization WHO. How to use the ICF: a practical manual for using the international classification of functioning, disability and health (ICF) : Exposure draft for comment. Geneva, WHO, 2013.

11. van Dulmen SA, van der Wees PJ, Bart Staal J et al. Patient reported outcome measures (proms) for goalsetting and outcome measurement in primary care physiotherapy, an explorative field study. Physiotherapy. 2017;103(1):66-72.

12. Prodinger B, Tennant A, Stucki G. Standardized reporting of functioning information on icf-based common metrics. Eur J Phys Rehabil Med. 2018;54(1):110-7.

13. Lee HJ, Song JM. Linking of items in two function-related questionnaires to the international classification of functioning, disability and health: Shoulder pain. J Kor Phys Ther. 2018;30(6):239-45.

14. Lee H, Nicholson LL, Adams RD et al. Development and psychometric testing of korean language versions of 4 neck pain and disability questionnaires. Spine. 2006;31(16):1841-5.

15. Cieza A, Geyh S, Chatterii S et al. ICF linking rules: an update based on lessons learned. J Rehabil Med. 2005;37(4):212-8. 
16. Ferreira M, Borges B, Rezende I et al. Are neck pain scales and questionnaires compatible with the international classification of functioning, disability and health? A systematic review. Disabil Rehabil. 2010;32(19): 1539-46.

17. Lee HJ, Song JM. Mapping items of functioning questionnaires into the international classification of functioning, disability and health: low back pain. J Kor Phys Ther. 2016;28(5):321-7.

18. Song JM, Lee HJ. Mapping items of functioning questionnaires into the international classification of functioning, disability and health: Stroke. J Kor Phys Ther. 2016;28(5):341-7. 